\title{
INFLUÊNCIA DA SANIDADE E DEFICIT HÍDRICO NA GERMINAÇÃO DE SEMENTES DE Carthamus tinctorius L. ${ }^{1}$
}

\author{
CIBELLEY VANÚCIA SANTANA DANTAS²; IVANICE BEZERRA SILVA3; GABRIELLE MACEDO PEREIRA4; \\ JOSEMIR MOURA MAIA ${ }^{5}$; JOÃO PAULO MATOS SANTOS LIMA ${ }^{6}$; CRISTIANE ELIZABETH COSTA DE MACEDO.
}

\begin{abstract}
RESUMO - A salinidade e o déficit hídrico são os fatores abióticos que têm afetado acentuadamente a produção de espécies vegetais de importância socioeconômica nas regiões áridas e semi-áridas. Portanto, o objetivo do presente trabalho foi de avaliar os efeitos do cloreto de sódio ( $\mathrm{NaCl}$ ) e do polietilenoglicol (PEG 6000), agentes estressores comumente utilizados para simular os estresses salino e hídrico, respectivamente, na germinação de sementes de cártamo (Carthamus tinctorius L.), uma oleaginosa da família Asteraceae. A germinação foi conduzida em sistema de rolo, com delineamento experimental de sete tratamentos osmóticos (controle; $-0,450 ;-0,852 ;-1,271 \mathrm{MPa}$ ), sendo três com concentrações isosmóticas de $\mathrm{NaCl}$ (100; 200 e 300mM) e PEG $(188,35 ; 267,75$ e 357,24 g/L), e cada tratamento com seis repetições. Durante a germinação, foram avaliados parâmetros como a porcentagem de germinação, o índice de velocidade de germinação (IVG), e três dias após o semeio, foram registrados o índice de crescimento relativo da radícula (ICRR) e a massa fresca dos eixos das plântulas. A porcentagem de germinação e o IVG não sofreram alterações significativas no tratamento osmótico de $-0,450 \mathrm{MPa}$ induzido por $\mathrm{NaCl}$ quando comparado com o controle, enquanto no mesmo tratamento, induzido pelo PEG, estes dois parâmetros apresentaram uma intensa diminuição e um leve aumento, respectivamente. O ICRR e a massa das plântulas apresentaram diminuições proporcionais à redução do potencial osmótico ao utilizar ambos os compostos. Com base nos resultados alcançados, pôde-se concluir que a germinação de sementes de cártamo é influenciada pelo tipo de estresse aplicado e sua respectiva dose. Adicionalmente, o estresse osmótico induzido por PEG 6000 é mais agressivo que o salino, e potenciais osmóticos mais baixos $(-0,851 \mathrm{e}-1,271 \mathrm{MPa})$ são limitantes para a germinação desta espécie.
\end{abstract}

Termos para indexação: cártamo, salinidade, déficit hídrico, biocombustível.

\section{INFLUENCE OF SALINITY AND WATER DEFICIT ON THE GERMINATION OF Carthamus tinctorius L. SEEDS}

\begin{abstract}
Salinity and water deficit are the main abiotic factors that adversely affect the production of economically important crops, especially in the arid and semiarid regions. The objective of the present study was to evaluate sodium chloride $(\mathrm{NaCl})$ and poliethyleneglycol
\end{abstract}

\begin{abstract}
${ }^{1}$ Submetido em 14/04/10. Aceito para publicação em 25/03/11. Trabalho financiado pelo Conselho Nacional de Desenvolvimento Científico e Tecnológico - CNPq.

${ }^{2}$ Graduanda em Ciências Biológicas, bolsista CNPQ-PIBIC do Lab. de Estudos em Biotecnologia Vegetal, DBG/UFRN, cibelley_rn@hotmail.com.
\end{abstract}

${ }^{3}$ Graduanda em C. Biológicas, DBQ/UFRN, ivanice_bezerra@hotmail.com.
${ }^{4}$ Graduanda em C. Biológicas, DBEZ/UFRN, gabrielle_mp1@yahoo.com.br. ${ }^{5}$ Prof. Dr., DBG/UFRN, jmouram@ufrnet.br.

${ }^{6}$ Prof. Dr., DBQ/UFRN, jpmatos@ufrnet.br.

${ }^{7}$ Profa.. Dra., Lab. de Estudos em Biotecnologia Vegetal, DBG/UFRN, Caixa Postal 1648, CEP: 59078-970, Natal-RN. cristianemacedo@ ufrnet.br. 
(PEG 6000), commonly used to mimic salt and water stress respectively, on the germination of Carthamus tinctorius L. seeds, an oleaginous species from the Asteraceae. Germination occurred on a paper towel roll system, with seven different osmotic treatments $(0,-0.450,-0.852,-1.271$ $\mathrm{MPa})$, obtained from iso-osmotic $\mathrm{NaCl}(100 ; 200$ and 300mM) and PEG (188.35; 267.75 and $357.24 \mathrm{~g} / \mathrm{L}$ ),concentrations. During germination and seedling establishment, the germination rate (\%), germination rate index (IVG), relative root growth index (ICRR) and seedling axis fresh weight were measured. The $\mathrm{NaCl}$ induced $-0.450 \mathrm{MPa}$ osmotic treatment did not result in significant changes in the germination rate and IVG compared to the controls, whereas these parameters were reduced and slightly increased respectively, with the same osmotic pressure induced by the PEG application. The ICRR and the seedling fresh weight showed steep reductions as osmotic pressure fell in both $\mathrm{NaCl}$ and PEG induced treatments. It can be concluded that the germination of $C$. tinctorius seeds is influenced in a stress and dose-specific manner. Moreover, the PEG induced osmotic stress is more aggressive than that induced by $\mathrm{NaCl}$, and lower osmotic pressures $(-0.851$ and $-1.271 \mathrm{MPa})$ limit germination of this species.

Index terms: safflower, salinity, water deficit, biofuels.

\section{INTRODUÇÃO}

Diversas culturas têm sido expostas a condições de múltiplos estresses que limitam seu desenvolvimento e conseqüentemente diminuem suas possibilidades de sobrevivência (Fanti e Perez, 2004). A salinidade e o déficit hídrico são os fatores abióticos que mais têm afetado negativamente a produção de espécies vegetais de importância socioeconômica nas regiões áridas e semiáridas, devido a irregularidades pluviais que impedem a lixiviação dos sais na superfície dos solos destas regiões (Ab'Sáber, 1999). Esses fatores afetam negativamente a germinação, o desenvolvimento vegetativo das culturas, a produtividade e, nos casos mais graves, causam a morte das plântulas (Oliveira e Gomes-Filho, 2009).

A germinação é a protrusão de uma das partes do embrião associada a algum sinal de crescimento (Borghetti e Ferreira, 2004). De acordo com Bewley e Black (1994), a primeira etapa da germinação ocorre com absorção de água pelas sementes, mediante embebição. Por isso, fatores como a salinidade e o déficit hídrico tem influência significativa sobre a germinação (Sousa et al., 2008). A observação da capacidade germinativa das sementes em condições de estresse é uma das metodologias mais difundidas para se determinar a tolerância das plantas (Fanti e Perez, 2004), pois a germinação corresponde a uma das fases mais críticas do ciclo de vida dos vegetais (Moterle et al., 2008).

O estresse salino e o déficit hídrico inibem ou retardam a germinação das sementes e o crescimento das plântulas devido aos efeitos iônico e osmótico (Munns, 2005). Em situações de baixa disponibilidade de água, a embebição é comprometida pela redução dos potenciais hídricos e o crescimento da plântula é afetado pela diminuição da expansão e do alongamento celular (Moterle et al., 2008). O excesso de sal causa restrição da captação de água devido à diminuição do potencial osmótico do substrato (Chaves et al., 2009), retardando a embebição das sementes ou o alongamento da raiz, além de provocar uma toxicidade nos tecidos devido ao acúmulo em excesso de íons $\mathrm{Na}^{+} \mathrm{e} \mathrm{Cl}^{-}$ (Ye et al., 2005; Esteves e Suzuki, 2008; Góis et al., 2008). Nas vias transpiratórias o excesso de íons provoca danos nos tecidos foliares levando a uma inibição mais acentuada no crescimento da planta (Munns et al., 2006).

Concentrações tóxicas desses íons afetam outros processos fisiológicos e metabólicos dos tecidos embrionários, incluindo a divisão e a diferenciação celular, a atividade de enzimas e a captação e distribuição de nutrientes. A toxicidade iônica pode ainda ocasionar o atraso da emergência das plântulas e da mobilização das reservas ou até diminuir a viabilidade das sementes (Misra e Dwivedi, 2004; Joshi et al., 2005; Esteves e Suzuki, 2008; Kumar et al., 2008; Munns e Tester, 2008; Voigt et al., 2009).

Estudos relacionados à fisiologia de sementes de oleaginosas são de fundamental importância para a introdução destas espécies no semi-árido e sua posterior utilização para a produção de biodiesel em áreas degradadas, contribuindo assim para a expansão de 
fronteiras agrícolas (Jones e Corlett, 1992; Brasil-MMA, 2000). Carthamus tinctorius L., uma espécie oleaginosa da família Asteraceae, pode ser considerada como uma opção agrícola para o semi-árido nordestino onde a seca e a salinidade são os fatores de estresse predominantes (Jones e Corlett, 1992). Esta espécie se destaca entre as oleaginosas, devido ao elevado teor de óleo (32 a 40\%) com $70 \%$ de acido linoléico e $30 \%$ de acido oléico, ideais para a produção de biodiesel (Vivas, 2002; Oplinger et al. 2010). Somando-se a estes fatores, o alto potencial desta espécie para o cultivo em regiões semi-áridas está ligado a sua resistência à escassez de água, às altas temperaturas, à baixa umidade relativa do ar e a sua capacidade de adaptação a diferentes condições de solo.

Torna-se, deste modo, necessário o estudo da germinação do cártamo para estimar o nível de resistência à seca e à salinidade gerando assim novos conhecimentos sobre a fisiologia dessa cultura que contribuirão para as áreas da agronomia, engenharia agrícola e biotecnologia. O objetivo do presente trabalho foi avaliar os efeitos do cloreto de sódio $(\mathrm{NaCl})$ e do polietilenoglicol (PEG 6000), agentes estressores utilizados para a simular os estresse salino e hídrico, respectivamente, na germinação de sementes de cártamo.

\section{MATERIAL E MÉTODOS}

\section{Material Vegetal}

As sementes de cártamo (Carthamus tinctorius L.) utilizadas neste trabalho foram fornecidas pela Empresa Rural Biodiesel, localizada na região de Eldorado, Mato Grosso do Sul. Os experimentos de germinação foram conduzidos no Laboratório de Estudos em Biotecnologia Vegetal, no Departamento de Biologia Celulare Genética, na Universidade Federal do Rio Grande do Norte, Natal - RN.

Germinação: o teste de germinação foi conduzido em sistema de rolo, seguindo os procedimentos descritos por Vieira e Carvalho (1994) com algumas modificações. Para tanto, as sementes íntegras foram desinfestadas com hipoclorito de sódio $0,2 \%(\mathrm{~m} / \mathrm{v})$ por 5 minutos sob agitação eventual, lavadas por quatro vezes com água destilada, sendo um minuto para cada lavagem. Posteriormente, as sementes foram distribuídas em folhas de papel toalha $\left(\right.$ Germitest $^{\circledR}-280 \times 380 \mathrm{~mm}$ ) umedecidas na proporção 1:5 vezes a massa do papel seco e organizadas em duas fileiras (cada fileira contendo dez sementes), sendo a primeira no terço superior e a segunda no terço mediano de duas folhas sobrepostas. Os rolos contendo as sementes foram colocados em câmera de germinação (BOD) na ausência total de luz por três dias, com temperaturas médias de $30^{\circ} \mathrm{C} \pm 1{ }^{\circ} \mathrm{C}$.

\section{Tratamentos e parâmetros de avaliação}

Durante a germinação, as sementes de cártamo foram submetidas a tratamentos com potenciais osmóticos equivalentes a $-0,450 ;-0,852 ;-1,271 \mathrm{MPa}$, obtidos a partir da aplicação de $\mathrm{NaCl}$ e polietilenoglicol (PEG 6000). Estes valores foram escolhidos para se determinar o nível de resistência desta espécie a condições moderadas e severas de estresse osmótico, durante a germinação, procurando assim simular as condições da região que a referida espécie será cultivada. As concentrações correspondentes de $\mathrm{NaCl}(0 ; 100 ; 200$ e $300 \mathrm{Mm})$ utilizadas neste estudo foram obtidas de acordo com a equação de Van't Hoff, utilizando a temperatura de $30{ }^{\circ} \mathrm{C}$ (Braga et al., 1999; Abebe et al., 2003). As concentrações de PEG $6000(0 ; 188,35 ; 267,75$ e $357,24 \mathrm{~g} / \mathrm{L}$ foram obtidas de acordo com a tabela citada por Villela et al. (1991). O PEG foi escolhido pelo grande número de estudos que tem utilizado este composto para simulação de estresse hídrico e por ser um polímero não iônico, de longa cadeia, inerte e não absorvido pelas raízes (Türkan et al., 2005). Durante a germinação, foi calculado o índice de velocidade de germinação (IVG) que foi obtido, diariamente, por meio da fórmula:

$\mathrm{IVG}=\left(\mathrm{N}_{1} \mathrm{G}_{1}+\mathrm{N}_{2} \mathrm{G}_{2}+\ldots+\mathrm{N}_{\mathrm{n}} \mathrm{G}_{\mathrm{n}}\right) /\left(\mathrm{G}_{1}+\mathrm{G}_{2}+\ldots+\mathrm{G}_{\mathrm{n}}\right)$

Onde: $\mathrm{G}_{1}, \mathrm{G}_{2}, \ldots \mathrm{G}_{\mathrm{n}}$ é o número de sementes germinadas no dia da observação; $\mathrm{N}_{1}, \mathrm{~N} 2, \ldots, \mathrm{N}_{\mathrm{n}}$ é o número de dias de observação, segundo Edmond e Drapalla (1958). A porcentagem de germinação, calculada por meio da fórmula:

$$
\mathrm{G}=\left(\sum \mathrm{n}_{\mathrm{i}} \cdot \mathrm{N}^{-1}\right) \cdot 100
$$

Onde: $\sum n_{\mathrm{i}}$ é o número total de sementes germinadas em relação ao número de sementes colocadas para germinar (Borghetti \& Ferreira, 2004) e três dias após o semeio foi calculado o índice de crescimento radicular relativo (ICRR) e computado a massa fresca dos eixos das plântulas. A análise do comprimento radicular foi realizada para cada plântula em escala milimétrica nos três dias de incubação e calculada através da formula:

\section{$\mathrm{ICRR}=\left(\mathrm{X}_{3^{\circ}} \operatorname{dia}-\mathrm{X}_{1^{\circ}} \operatorname{dia}\right) / \mathrm{N}$}

Onde ICRR é o indice de crescimento relativo da radícula; e o $\mathrm{X}_{1^{\circ: 3^{\circ}}}$ é a média do comprimento radicular por dia, e $\mathrm{N}$ corresponde ao número total de dias de observação.

O experimento foi conduzido em delineamento inteiramente casualizado consistindo de 7 (sete) tratamentos 
(0; S1; S2; S3; P1; P2; P3) e 6 (seis) repetições da unidade experimental. Cada repetição consistia de seis rolos contendo 20 sementes. Os resultados obtidos foram submetidos à análise de variância seguida de comparação de médias pelo teste de Tukey em nível de significância de 5\%.

\section{RESULTADOS E DISCUSSÃO}

A redução no potencial osmótico, induzida tanto por tratamento com $\mathrm{NaCl}$, como por PEG-6000, provocou alterações nos parâmetros germinativos de sementes de cártamo, embora em diferentes intensidades. A porcentagem de germinação diminuiu proporcionalmente ao aumento do potencial osmótico exercido pelo $\mathrm{NaCl}$ (Figura 1A). $\mathrm{Na}$ ausência de sal ( $0 \mathrm{mM} \mathrm{de} \mathrm{NaCl}$ - controle) as porcentagens de germinação das sementes atingiram níveis superiores a 70\%, a partir do segundo dia após a semeadura. Sementes tratadas com $100 \mathrm{mM}$ de $\mathrm{NaCl}$ apresentaram porcentagem de germinação igual ou superior a $50 \%$ e, portanto, não diferiram significativamente do controle. Contrariamente, as porcentagens de germinação de sementes tratadas com 200 e $300 \mathrm{mM}$ de $\mathrm{NaCl}$ foram menores que $50 \%$, em relação ao controle. No estresse osmótico induzido por PEG 6000 houve uma redução mais acentuada na porcentagem de germinação do que os tratamentos equivalentes com $\mathrm{NaCl}$ (Figura 1B). Neste experimento, as porcentagens de germinação do controle foram de 40; 67 e 74\%, enquanto que as sementes submetidas ao potencial osmótico de -0,450 MPa de PEG 6000 (isosmótica ao tratamento com $100 \mathrm{mM}$ de $\mathrm{NaCl}$ ) apresentaram porcentagens de germinação de $0 ; 8$ e $16 \%$ para o primeiro, segundo e terceiro dias, respectivamente. Além disso, as sementes submetidas aos potenciais de $-0,851$ e -1,27 MPa não germinaram.

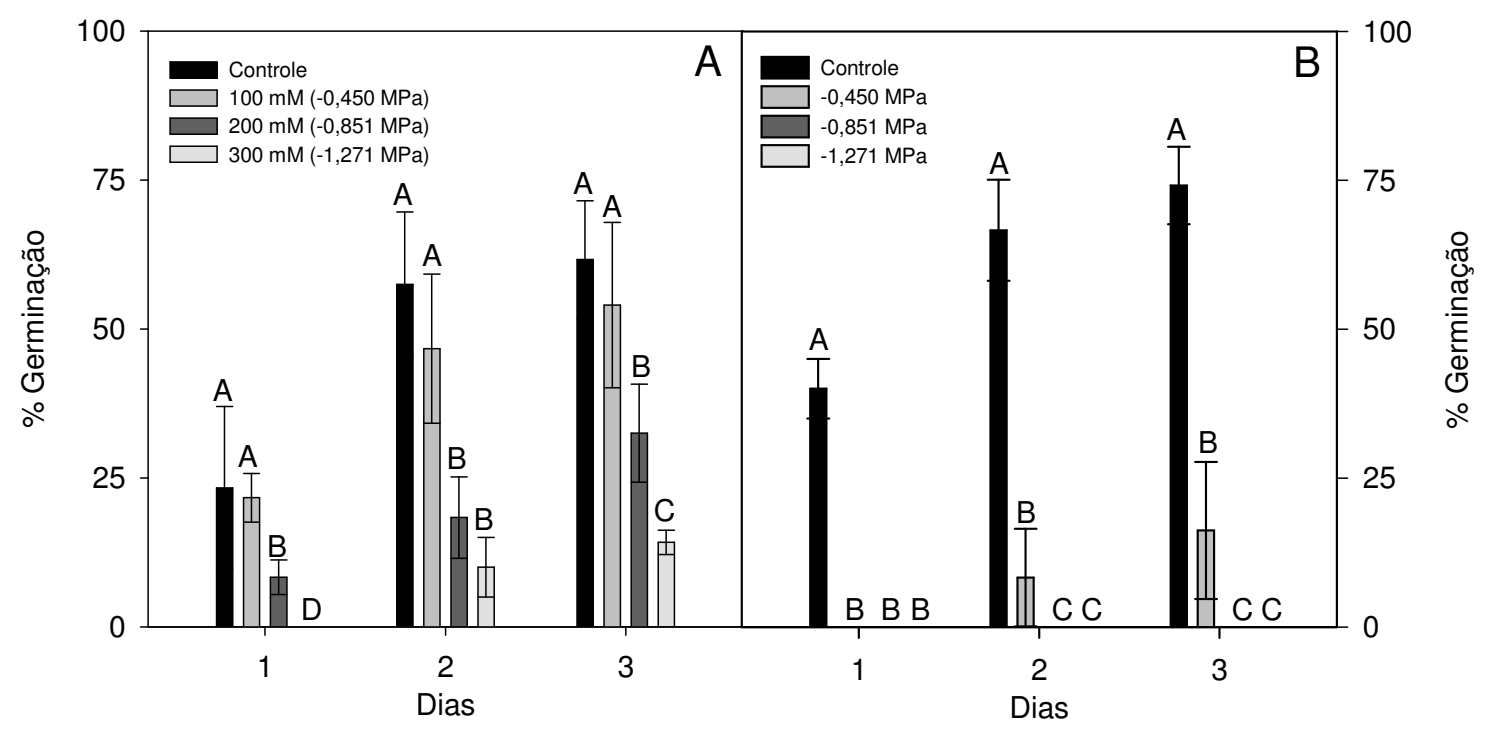

FIGURA 1. Porcentagem de germinação de sementes de $C$. tinctorius, até 3 dias após o semeio, submetidas a diferentes concentrações de $\mathrm{NaCl}$ (A) e a diferentes tratamentos osmóticos (MPa) induzidos por PEG 6000 (B). Letras iguais, entre os tratamentos e avaliadas a cada dia, indicam diferenças não-significativas entre as médias, de acordo com o teste de Tukey a $5 \%$ de probabilidade.

Diversos autores (Ulisses et al., 2000; Zhu, 2001; Flexas et al., 2004; Ashraf e Foolad, 2007) relatam que tanto o estresse hídrico quanto o salino induzem estresse osmótico, provocando nas sementes uma seca fisiológica, causada pelo baixo potencial osmótico. Isto dificulta a absorção de água pelas sementes e, consequentemente, retarda os processos germinativos (Fantin e Perez, 2004). Segundo O'Leary (1995), as sementes também são sensíveis à salinidade e, quando semeadas empregando soluções salinas, ocorre inicialmente uma redução na taxa 
de absorção de água e posteriormente uma diminuição na velocidade dos processos fisiológicos e bioquímicos (Flowers, 2004).

A eficiência da germinação de sementes de cártamo, sob tratamentos salino e osmótico, também foi avaliada por meio do índice de velocidade de germinação (IVG) (Figura 2A e 2B). A salinidade causou retardamento na germinação das sementes, que foi proporcional ao aumento da concentração de $\mathrm{NaCl}$ (Figura 2A). Contudo, o tratamento com $100 \mathrm{mM}$ de $\mathrm{NaCl}$ não diferiu significativamente do controle, enquanto os tratamentos com 200 e $300 \mathrm{mM}$ de $\mathrm{NaCl}$ causaram um atraso de aproximadamente $24 \mathrm{~h}$ na germinação, comparativamente ao controle. Já o tratamento com PEG 6000 retardou o IVG em aproximadamente $12 \mathrm{~h}$, a partir do potencial osmótico -0,450 MPa de PEG 6000 (Figura 2B). Resultados semelhantes, usando PEG 6000 e/ou NaCl foram observados em sementes de coentro (Filgueira, 1993), alface (Viana et al., 2001) e plântulas de melão (Ferreira et al., 2007). De fato, a primeira e mais sensível resposta à redução do potencial osmótico do meio de embebição é à redução da turgescência celular que leva, conseqüentemente, à diminuição do crescimento, uma vez que a divisão, o alongamento e diferenciação celular são afetados nos diversos estádios fisiológicos (Fanti e Perez, 2004).

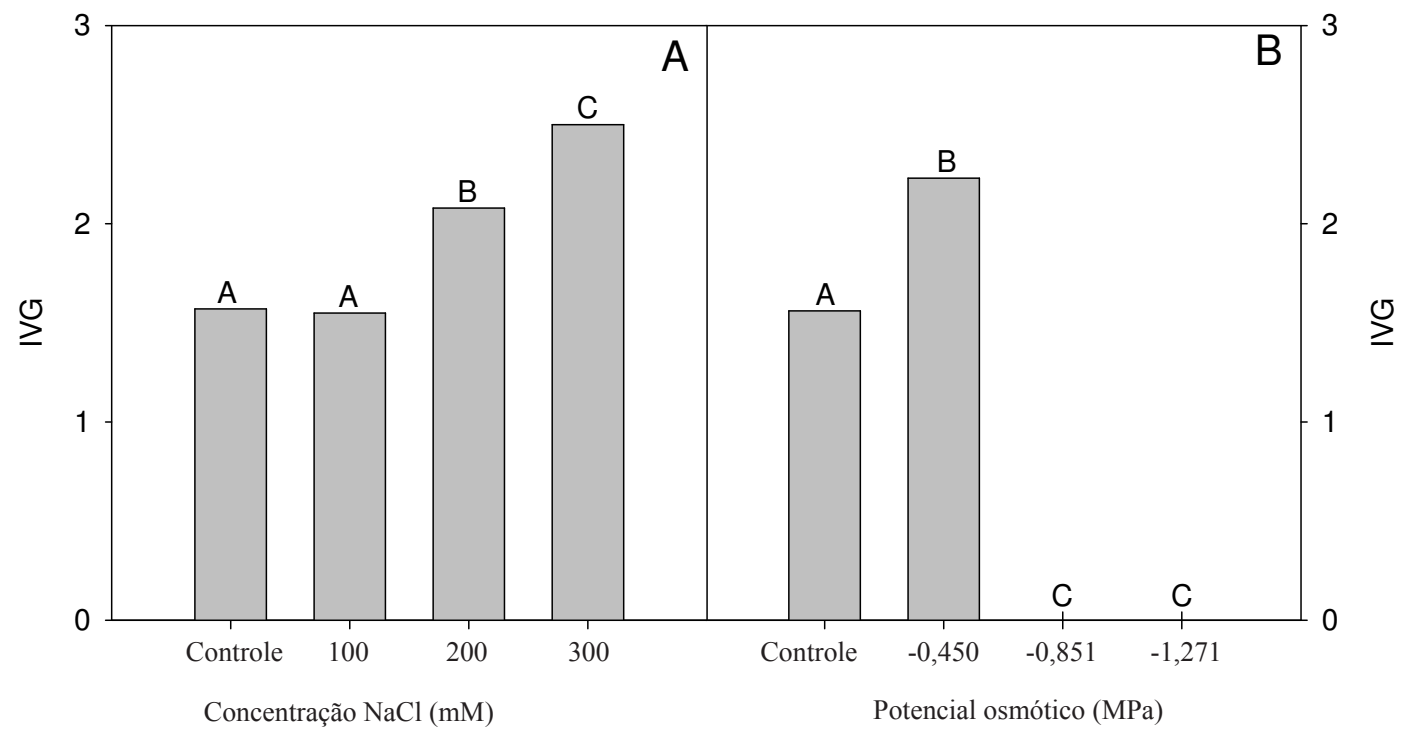

FIGURA 2. Índice de velocidade de germinação (IVG) de sementes de $C$. tinctorius, submetidas a diferentes concentrações de $\mathrm{NaCl}$ (A) e a diferentes tratamentos osmóticos (MPa) induzidos por PEG 6000 (B). Letras iguais indicam diferenças não-significativas entre as médias, de acordo com o teste de Tukey a $5 \%$ de probabilidade.

O índice de crescimento relativo da radícula (ICRR) também decresceu com a diminuição do potencial osmótico induzida pelas concentrações mais elevadas de $\mathrm{NaCl}$ e PEG 6000 (Figura 3A e 3B). De acordo com Munns e Tester (2008) o crescimento radicular pode ser restringido tanto pelo déficit hídrico induzido pela osmolaridade elevada da solução, quanto pela toxicidade iônica envolvendo danos metabólicos e fisiológicos. De fato, os tratamentos com 200 e $300 \mathrm{mM}$ de $\mathrm{NaCl}$, induziram uma diminuição do ICRR superior a 50\%, comparativamente ao controle (Figura 3A). Resultados similares foram observados em diversas espécies, tais como, sorgo (Wahid et al., 1998), mamona (Pinheiro et al., 2008) e pinhão manso (Silva et al., 2009). Similarmente, nas sementes submetidas ao estresse osmótico induzido por PEG 6000, o tratamento com -0,450 MPa não afetou o crescimento radicular, enquanto os tratamentos com $-0,851$ e -1,271 MPa (isosmóticos aos tratamentos com 200 e 300 $\mathrm{mM}$ de $\mathrm{NaCl}$ ) causaram $100 \%$ de inibição do crescimento 
das raízes, quando avaliado pelo ICRR (Figura 3B).

Os resultados obtidos para o ganho de massa fresca dos eixos das plântulas foram semelhantes aos do crescimento radicular (Figura 4A e 4B). Aqueles tratados com $\mathrm{NaCl}$ apresentaram 17; 39 e 44\% de redução no teor de massa fresca de embrião, para as doses de 100; 200 e $300 \mathrm{mM}$ de $\mathrm{NaCl}$, respectivamente (Figura 4A). Contrariamente, sementes submetidas aos tratamentos com PEG 6000 tiveram suas massas reduzidas a aproximadamente $50 \%$ em todos os tratamentos (Figura 4B).

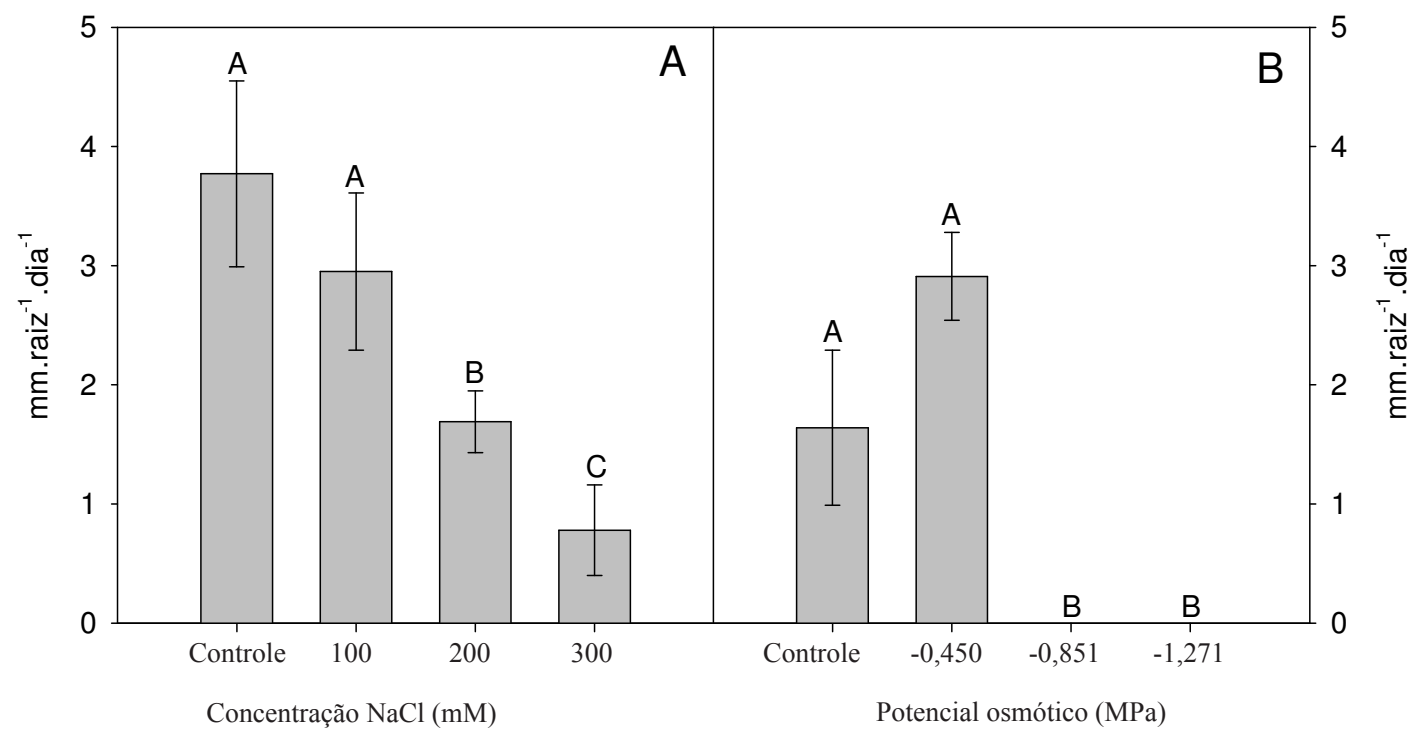

FIGURA3. Índice de crescimento radicular relativo na germinação de sementes $C$. tinctorius, submetidas a diferentes concentrações de $\mathrm{NaCl}(\mathrm{A})$ e a diferentes tratamentos osmóticos (MPa) induzidos por PEG 6000 (B). Letras iguais indicam diferenças não-significativas entre as médias, de acordo com o teste de Tukey a $5 \%$ de probabilidade.

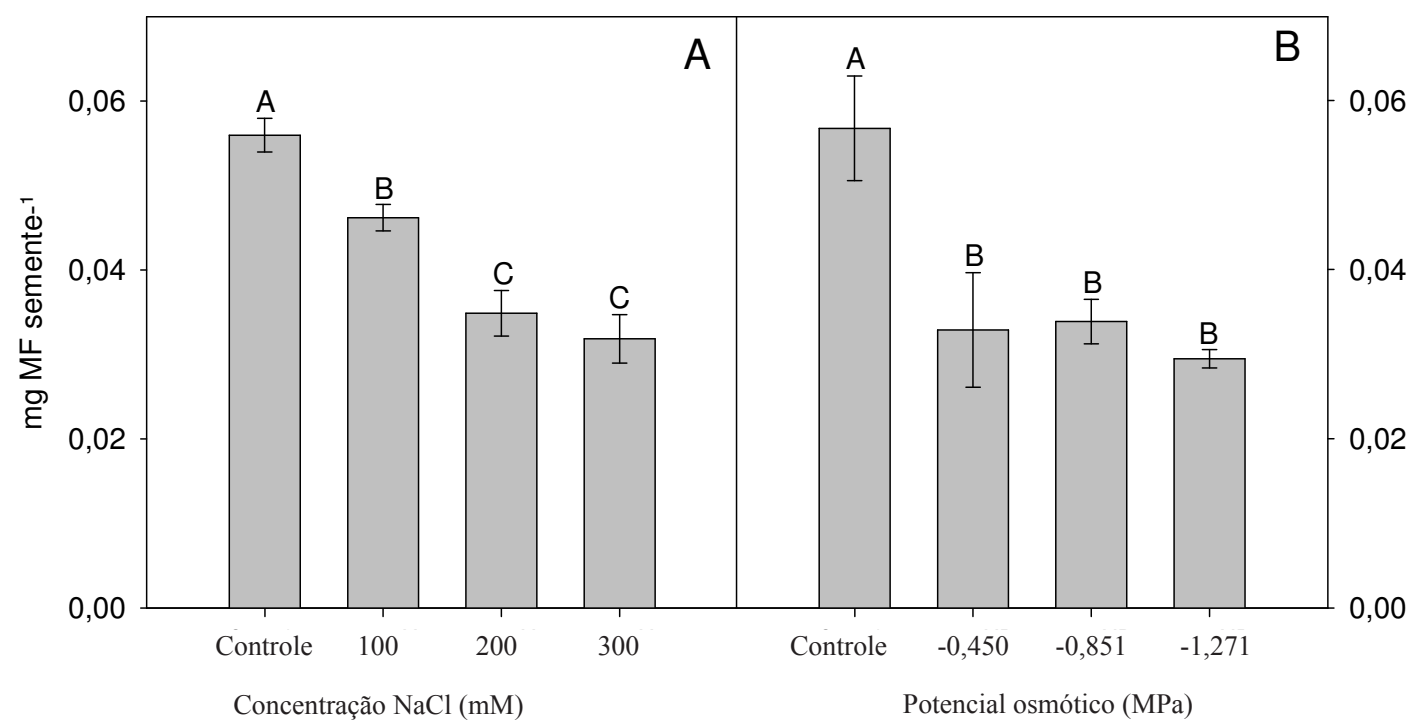

FIGURA 4. Massa fresca dos eixos das plântulas de $C$. tinctorius, submetidas a diferentes concentrações de $\mathrm{NaCl}$ (A) e a diferentes tratamentos osmóticos (MPa) induzidos por PEG 6000 (B). Letras iguais indicam diferenças não-significativas entre as médias, de acordo com o teste de Tukey a $5 \%$ de probabilidade. 
De acordo com os resultados avaliados e com base nos parâmetros estudados as sementes de Carthamus tinctorius mostraram-se mais resistentes ao tratamento com $\mathrm{NaCl}$ do que com PEG 6000. No entanto, ambos os agentes estressores reduziram a porcentagem de germinação proporcionalmente ao aumento das concentrações dos tratamentos, embora o efeito do PEG 6000 tenha sido mais severo. Neste contexto, a germinação das sementes, submetidas ao PEG 6000, nas menores potenciais osmóticos $(-0,851$ e $-1,271$ $\mathrm{MPa}$ ), foi totalmente inibida. Adicionalmente, verificouse que as sementes de cártamo são mais sensíveis aos tratamentos com PEG 6000. Diferentemente do $\mathrm{NaCl}$ que pode ser transportado através das membranas, este soluto não se acumula nos tecidos vegetais. A absorção de água pelas sementes na presença de $\mathrm{NaCl}$ é maior do que na presença de PEG, quando se comparam soluções de potenciais osmóticos similares, pois os íons podem ser transportados e assim contribuir para um decréscimo do potencial osmótico interno, levando a absorção de água e iniciação da germinação (Almansouri et al., 2001). Ainda segundo estes autores, o efeito inibitório do PEG pode não estar apenas relacionado a absorção de água. De fato, não houve diferença significativa no peso fresco das sementes submetidas ao PEG, nos diferentes potenciais osmóticos, embora apenas as sementes submetidas ao potencial osmótico de $-0,450 \mathrm{MPa}$ tenham apresentado germinação.

Vale destacar que, embora o cártamo seja considerado uma planta resistente a ambientes e condições extremas, neste trabalho e nas condições experimentais estabelecidas, as sementes de cártamo não foram capazes de resistir a potenciais osmóticos muito baixos. Assim, embora esta espécie seja caracterizada como de clima semi-árido e, mesmo sendo capaz de germinar em presença de $\mathrm{NaCl}$, possivelmente os demais estádios fisiológicos seriam afetados.

\section{CONCLUSÕES}

A geminação das sementes de Carthamus tinctorius L. submetidas a estresses salino e osmóticos é influenciada pelo tipo de estresse e a respectiva dose.

Os potenciais osmóticos mais baixos $(-0,851$ e -1,271 MPa) de PEG 6000 mostram-se limitantes para a germinação de sementes de Carthamus tinctorius L.

O estresse osmótico induzido por PEG é mais severo que o salino na germinação de Carthamus tinctorius L.

\section{AGRADECIMENTOS}

Ao Conselho Nacional de Desenvolvimento Científico e Tecnológico - CNPq, pelo apoio financeiro.

\section{REFERÊNCIAS}

ABEBE, T.; GUENZI, A.C.; MARTIN, B.; CUSHMAN, J.C. Tolerance of Mannitol-accumulating transgenic wheat to water stress and salinity. Plant Physiology, v.131, p.1748-1755, 2003.

AB'SÁBER, A.N. Sertões e sertanejos: uma geografia humana sofrida. Estudos Avançados, v.13, p.7-59, 1999.

ALMANSOURI, M.; KINET, J.-M.; LUTTS, S. Effect of salt and osmotic stresses on germination in durum wheat (Triticum durum Desf.). Plant and Soil, v.231, p.243-254. 2001.

ASHRAF, M.; FOOLAD, M.R. Roles of glycine betaine and proline in improving plant abiotic stress resistance. Environmental and Experimental Botany, v.59, n.2, p.206-216, 2007.

BRAGA, L.F.; SOUSA, M.P.; BRAGA, J.F.; DE SÁ, M.E. Efeito da disponibilidade hídrica do substrato na qualidade fisiológica de sementes de feijão. Revista Brasileira de Sementes, v.21, n.2, p.95-102, 1999.

BEWLEY, J.; BLACK, M. Seed: physiology of development and germination. New York: Plenum Press, 1994. 445p.

BORGHETTI, F.; FERREIRA, A.G. Interpretação de resultados de germinação. In: FERREIRA, A.G.; BORGHETTI, F. (Ed.) Germinação: do básico ao aplicado. Porto Alegre: Artmed, 2004. p.209-222.

BRASIL. Ministério do Meio Ambiente. Política Nacional de Biodiversidade. Brasília, DF: MMA, 2000.

CHAVES, M.M.; FLEXAS, J.; PINHEIRO, C. Photosynthesis under drought and salt stress: regulation mechanisms from whole plant to cell. Annals of Botany, v.103, n.4, p.551-560, 2009.

EDMOND, J.B.; DRAPALLA, W.J. The effects of temperature, sand and soil, and acetone on germination of okra seed. Proceedings of the American Society for Horticultural Science, v.71, p.428-443, 1958.

ESTEVES, B.S.; SUZUKI, M.S. Efeito da salinidade sobre as plantas. Oecologia Australis, v.12, n.4, p.662-679, 2008 . 
FANTI, S.C.; PEREZ, J.G.A. Processo germinativo de sementes de paineira sob estresses hídrico e salino. Pesquisa Agropecuária Brasileira, v.39, p.903-909, 2004.

FERREIRA, G.S.; TORRES, S.B.; COSTA, A.R.F.C. Germinação e desenvolvimento inicial de plântulas de meloeiro em diferentes níveis de salinidade da água de irrigação. Revista Caatinga, v.20, n.3, p.181-185, 2007.

FILGUEIRA, R.F. Efeito de diferentes níveis de salinidade do solo no comportamento de duas cultivares de coentro (Coriandum sativum L.). 1993. 46f. Monografia (Especialização) - Escola Superior de Agricultura de Mossoró (ESAM), Mossoró, 1993.

FLEXAS, J.; BOTA, J.; LORETO, F.; CORNIC, G.; SHARKEY, T.D. Diffusive and metabolic limitations to photosynthesis under drought and salinity in C3 plants. Plant Biology, v.6, p.269-279, 2004.

FLOWERS, T.J. Improving Crop Salt Tolerance. Journal of Experimental Botany, v.55, n.396, p.307-319, 2004.

GÓIS, V.A.; TORRES, S.B.; PERREIRA, R.A. Germinação de sementes de maxixe submetidas a estresse salino. Revista Caatinga, v.21, n.4, p.64-67, 2008.

JONES, H.G.; CORLETT, J.E. Current topics in drought physiology. Journal of Agricultural Science, v.119, p.291-296, 1992.

JOSHI, A.J.; MALI, B.S.; HINGLAJIA, H. Salt tolerance at germination and early growth of two forage grasses growing in marshy habitats. Environmental and Experimental Botany, v.54, p.267-274, 2005.

KUMAR, N.; PAMIDIMARRI, S.D.V.N.; KAUR, M.; BORICHA, G.; REDDY, M.P. Effects of $\mathrm{NaCl}$ on growth, ion accumulation, protein, proline contents and antioxidant enzymes activity in callus cultures of Jatropha curcas. Biologia, v.63, n.3, p.378-382, 2008.

MISRA, N.; DWIVEDI, U.N. Genotypic difference in salinity tolerance of green gram cultivars. Plant Science, v.166, p.1135-1142, 2004.

MOTERLE, L.M.; SCAPIM, C.A.; BRACCINI, A.L.; RODOVALHO, M.A.; R.R. BARRETO Influência do estresse hídrico sobre o desempenho fisiológico de sementes de híbridos simples de milho-pipoca. Ciência e Agrotecnologia, v.32, p.1810-1817, 2008.

MUNNS, R. Genes and salt tolerance: bringing them together. New Phytologist. v.167, n.3, p.645-663, 2005.

MUNNS, R.; JAMES, R.A.; LÄUCHLI, A. Approaches to increasing the salt tolerance of wheat and other cereals.
Journal of Experimental Botany, v.57, n.5, p.1025-1043, 2006

MUNNS, R.; TESTER, M. Mechanism of salinity tolerance. Annual Review of Plant Biology, v.59, p.651-681, 2008.

O'LEARY, J.W. Adaptive components of salt tolerance. In: PESSARAKLI, M. (Ed). Handbook of plant and crop physiology. New York: Marcel Dekker, 1995. p.577-585.

OLIVEIRA, A.B.; GOMES FILHO, E. Germinação e vigor de sementes de sorgo forrageiro sob estresse hídrico e salino. Revista Brasileira de Sementes. v.31, n.3, p, 2534, 2009.

OPLINGER, E.S.; PUTNAM, D.H.; KAMINSKI, A.R.; HANSON, C.V.; OELKE, E.A.; SCHULTE, E.E.; DOLL, J.D. Sesame. In: Alternative Field Crops Manual. Disponível: $<$ www.hort.purdue.edu/newcrop/afcm/sesame. html>. Acesso em: 10 mar 2010.

PINHEIRO, H.A.; SILVA, J.V.; ENDRES, L.; FERREIRA, V.M.; CÂMARA, C.A; CABRAL, F.F; OLIVEIRA, J.F.; CARVALHO, L.W.T.; SANTOS, J.M.; SANTO-FILHO, B.G. Leaf gas exchange, chloroplastic pigments and dry matter accumulation in castor bean (Ricinus communis L.) seedlings subjected to salt stress conditions. Industrial Crops and Products, v.27, p.385-392, 2008.

SILVA, E.N.; SILVEIRA, J.A.G.; RODRIGUES, C.R.F.; DUTRA, A.T.B.; ARAGÃO, R.M. Acúmulo de íons e crescimento de pinhão-manso sob diferentes níveis de salinidade. Revista Ciência Agronômica, v.40, n.2, p.240246, 2009.

SOUSA,M.P.;BRAGAL.F.;BRAGA,J.F.;DELACHIAVE, M.E.A. Estresses hídrico e salino no processo germinativo das sementes de Plantago ovata Forsk. (Plantaginaceae). Revista Árvore, v.32, p.33-38. 2008.

TÜRKAN, I., BOR, M., OZDEMIR, F., KOCA, H. Differential responses of lipid peroxidation and antioxidants in the leaves of drought-tolerant $P$. acutifolius Gray and drought-sensitive $P$. vulgaris $\mathrm{L}$. subjected to polyethylene glycol mediated water stress. Plant Science, v.168, n.1, p.223-231, 2005.

ULISSES, C.; CAMARA, T.R.; WILLADINO, L.; MEUNIER, I.; ROCHA, P.S.G.; ALBUQUERQUE, C. Seleção in vitro de gemas de bananeira 'Nanica' tolerante à salinidade. Scientia Agricola, v.57, n.4, p.667-670, 2000.

VIANA, S.B.A.; FERNANDES, P.D.; GHEYI, H.R. Germinação e formação de mudas de alface em diferentes níveis de salinidade de água. Revista Brasileira de Engenharia Agrícola e Ambiental, v.5, n.1, p.62-66, 2001. 
VIEIRA, R.D.; CARVALHO, N.M. Testes de vigor de sementes. Jaboticabal: FUNEP, 1994. 164p.

VILLELA, F.A.; DONI FILHO, L.; SEQUEIRA, E.L. Tabela de potencial osmótico em função da concentração de polietileno glicol 6000 e da temperatura. Pesquisa Agropecuária Brasileira, v.26, p.1957-1968, 1991.

VIVAS, M.J. Culturas Alternativas - Cártamo, Sésamo e Camelina. Melhoramento, v.38, p.183-192, 2002.

VOIGT, E.L.; ALMEIDA, T.D.; CHAGAS, R.M.; PONTE, L.F.A.; VIÉGAS, R.A.; SILVEIRA, J.A.G. Source-sink regulation of cotyledonary reserve mobilization during cashew (Anacardium occidentale) seedling establishment under $\mathrm{NaCl}$ salinity. Journal of Plant Physiology, v.166, p.80-89, 2009.
WAHID, A.; JAVED, I.-H.; ALI, I.; BAIG, A.; RASUL, E. Short term incubation of sorghum caryopses in sodium chloride levels: changes in some pre- and post-germination physiological parameters. Plant Science, v.139, p.223232, 1998.

YE, Y.; TAM, N.F.-Y.; LU, C.-Y.; WONG, Y.-S. Effects of salinity on germination, seedling growth and physiology of three salt-secreating mangrove species. Aquatic Botany, v.83, p.193-205, 2005.

ZHU, J.K. Cell signaling under salt, water and cold stress. Current Opinion in Plant Biology, v.4, p.401-406, 2001. 